\title{
EL VIZCONDE DE RIO BRANCO Y LA PAZ PLATINA: LA DIPLOMACIA Y EL DERECHO EN SUS DISCURSOS PARLAMENTARES
}

\author{
THE VISCOUNT OF RIO BRANCO AND THE PEACE IN THE PLATA: DIPLOMACY AND LAW IN HIS
}

PARLIAMENTARY SPEECHES

\author{
O VISCONDE DO RIO BRANCO E A PAZ PLATINA: DIPLOMACIA E DIREITO EM SEUS
}

DISCURSOS PARLAMENTARES

Caio Henrique Dias Duarte*

\begin{abstract}
Resumen:
La diplomacia de Brasil es históricamente orientada por una grande articulación legal, desde el inicio de la consolidación de sus fronteras en el Tratado de Madrid (1750) con Alexandre de Gusmão. Pero la consolidación de sus principios norteadores, como el uti possidetis, se pasó de facto con la actuación del Vizconde de Uruguay y del Vizconde del Rio Branco tras la política imperial en el Plata entre los años 1850 y 1870, cuando actuaron como diplomatas y también Cancilleres en el Ministério de Negócios Estrangeiros. Este artículo buscará investigar los aspectos legales de la visión de Rio Branco sobre el planeamiento y la actuación política del Imperio de Brasil en el Plata. Para eso, será hecho un análisis de sus discursos sobre política exterior y el Plata en el Parlamento Imperial, de 1855 a 1875 . Así se busca comprender la importancia de su actuación en la Cuestión Platina, que se dio en el apogeo del Imperio, cuando se pasaron las intervenciones en las repúblicas platinas y también la Guerra de Paraguay, firmando las concepciones de fronteras y de isonomía entre los Estados como fundamentales en la diplomacia brasileña. De tal forma, la metodología utilizada será la de, tras un análisis de los discursos del Vizconde como fuentes primarias, observar a los fundamentos y la articulación de la visión jurídica de la actuación de Brasil en el Plata en su diplomacia, considerando el Derecho como práctica en la estabilización de la región.

Palabras clave: Vizconde de Río Branco. Historia del Derecho Internacional. Historia Diplomática. Diplomacia Brasileña. Historia de Brasil. Historia de las Relaciones Internacionales. Historia de Sud América.
\end{abstract}

\begin{abstract}
:
Since the beginning of the consolidation of its borders with the Treaty of Madrid (1750) by Alexandre de Gusmão, Brazilian diplomacy has been historically oriented by a strong legal articulation. But the consolidation of its guiding principles, such as the uti possidetis, only came to be under the Viscounts of Uruguay and of Rio Branco under the Imperial policy to the Plata basin between 1850s and 1870s, when they acted as diplomats and Ministers in the Ministry of Foreign Affairs. This paper intends to investigate the legal aspects of Rio Branco's vision on the policy planning
\end{abstract}

* Estudante da Faculdade de Direito do Largo de São Francisco, USP. E-mail: caiohdduarte@gmail.com. 
and actions of the Empire of Brazil in the Plata. Looking at his speeches on foreign policy and the Plata in the Imperial Parliament between 1855 and 1875, it aims to understand the importance of his actions in the Platine Issue, that happened in the apogee of the Empire, with the interventions in the platine republics and also the Paraguayan War, settling what would become the fundamental Brazilian conceptions of borders and of equality among states. Therefore, the methodology used will be that of, under an analysis of Viscount's speeches as primary sources, one can observe the foundations and the articulation of the legal vision of Brazil's actions in the Plata in its diplomacy, considering Law as a practice in the stabilization of the region.

Keywords: Viscount of Rio Branco. History of International Law. Diplomatic History. Brazilian Diplomacy. History of Brazil. History of International Relations. History of South America.

\begin{abstract}
Resumo:
A diplomacia do Brasil é historicamente orientada por uma grande articulação legal, desde o início da consolidação de suas fronteiras com o Tratado de Madrid (1750) e Alexandre de Gusmão. Mas a consolidação de seus princípios norteadores, como o uti possidetis, se deu de fato com a atuação do Visconde do Uruguai e do Visconde do Rio Branco na política imperial no Prata entre os anos 1850-1870, quando atuaram como diplomatas e chanceleres no Ministério dos Negócios Estrangeiros. Este artigo buscará investigar os aspectos legais da visão de Rio Branco sobre o planejamento e a atuação da política do Império do Brasil no Prata. Para isso, será feita uma análise de seus discursos sobre política exterior e o Prata no Parlamento Imperial de 1855 a 1875. Assim, se busca compreender a importância de sua atuação na Questão Platina, que se deu no apogeu do império, quando aconteceram as intervenções nas repúblicas platinas e também a Guerra do Paraguai, firmando as concepções de fronteiras e de isonomia entre os Estados como fundamentais à diplomacia brasileira. De tal forma, a metodologia utilizada será a de, por meio de uma análise dos discursos do Visconde como fontes primárias, observar os fundamentos e a articulação da visão jurídica da atuação do Brasil no Prata em sua diplomacia, considerando o Direito como prática na estabilização da região.

Palavras-chave: Visconde do Rio Branco. História do Direito Internacional. História Diplomática. Diplomacia Brasileira História do Brasil. História das Relações Internacionais. História da América do Sul.
\end{abstract}

Introducción

El objetivo de este artículo es discutir, bajo la práctica representada por los discursos parlamentares de José Maria da Silva Paranhos, el Vizconde de Rio Branco, la influencia de sus concepciones de visión diplomática y jurídica en el ámbito del derecho internacional y la actuación diplomática de Brasil. Considerando la pequeña exploración de su obra es necesario no solo compilar sus posiciones y ideas acerca de cuestiones momentáneas, pero también demostrar cómo son parte de conceptos generales basilares a la diplomacia brasileña. 
Así, aunque brevemente, mirando a sus discursos parlamentares, ${ }^{1}$ (i) haremos una retrospectiva de la práctica jurídica como fundamental a la diplomacia brasileña, explorando la figura de Paranhos como (ii) promotor de un interés nacional brasileño, especialmente en el embate político y jurídico bajo las cuestiones platinas, nominalmente (iii) las fronteras, (iv) para ilustrar la visión de una pax brasiliana del Vizconde en la región y su legado hasta hoy como lugar de memoria en la identidad nacional brasileña.

\section{Paranhos, la cultura del bacharelismo y el Plata}

Al mirar al derecho y la diplomacia en el Brasil imperial, no se puede simplemente observar los enunciados de los relatos historiográficos de la época o el texto de los tratados, sino también la práctica, la elaboración de los conceptos en el debate público, su relación con la cultura y las instituciones en la sociedad. Son las actuaciones diplomática y la político-jurídica indisociables (FONSECA JÚNIOR, 1998, p. 356) y así la cultura jurídica de la élite imperial influencia fuertemente la práctica diplomática (CERVO, 1994, p. 26). Así, considerando el derecho como un punto de referencia, lo analizamos en la perspectiva del juego de lenguaje, buscando comprender el carácter interdependiente de los trazos de una cultura, una identidad nacional (SOUZA, 2017, p. 21-25).

Antonio Candido trae dos conceptos importantes para comprender tal interdependencia: Sobre la construcción de las ideas, dijo Candido de una mezcla entre el universalismo y el particularismo, que influencia la élite política a adoptar conceptos como los de el iluminismo europeo (SÁ, 2006, p. 57). Esta mezcla se resume en la formulación de Roberto Schwarz de que Brasil sería un espacio de las ideias fuera del lugar, donde "con método, se atribuye la independencia a la dependencia, utilidad al capricho, universalidad a las excepciones, mérito a los parientes, co-igualdad al privilegio" (SCHWARZ, 1992, p. 18).

Queda la comunicación en la esfera pública bajo la influencia de la matriz católica y del formalismo jurídico de Coimbra, una cultura en que los hombres públicos de la élite deben privilegiar actuar con erudición en una lógica performática, una tradición de auditorio (SÁ, 2006, p. 38), es decir, la creación de un espacio de agencia política donde los actores legítimos son solo los egresos de las escuelas jurídicas que integran la elite imperial, latifundiaria y aristocrática, el bacharelismo (RODRIGUES, 1966, p. 54). ${ }^{2}$

1 En los discursos y excertos, hice la traducción del portugués al español de manera a facilitar la comprensión del lector.

2 Sobre la cultura de auditorio y el bacharelismo, se puede mencionar Literatura e Sociedade (1965) de 
Así se tiene fundamental el debate público en el Parlamento, objeto de nuestro análisis. Son los diputados, senadores y ministros los bacharéis que ponen las ideias fuera del lugar en la construcción del Estado y de la Identidad de Brasil.

La diplomacia tubo papel fundamental en la formación de la identidad nacional brasileña, afirmando la visión de un imperio europeo en los trópicos republicanos de Latinoamérica, y sigue teniendo un fuerte vínculo con el uso del derecho como herramienta de consecución de los objetivos internacionales de Brasil. Define el Embajador Paulo Roberto de Almeida:

El derecho internacional de Brasil, si existe -parece que síno se debe tanto al propio cuerpo diplomático del Itamaraty cuanto a los juristas colocados a su servicio, desde los tiempos del Ministerio de los Negocios Extranjeros (MNE) en el Segundo Reinado (...) El Itamaraty siempre fue más característicamente jurídico que de cualquier otra orientación doctrinal que tenga marcado su existencia casi bisecular (ALMEIDA, 2016, p. 241-242).

Representación de la estructura social que construyó el Brasil de hoy, el Ministerio de las Relaciones Exteriores, o Itamaraty, ${ }^{3}$ puede ser considerado como lugar de memoria (NORA, 1984. p. 24-25) en este sentido, así como importantes cancilleres que comandaron la casa. El más importante de ellos, José Maria da Silva Paranhos Júnior, el Barón de Rio Branco, ${ }^{4}$ representa esta definición con clareza, así que su operación del derecho internacional en la consolidación pacífica de las fronteras de Brasil le hizo "especie de nombre tutelar (...) Dios Termeiro (Terminus) de nuestra integridad nacional" (BARBOSA, 2002, p. 17) en las palabras de Ruy Barbosa, consagrando, "la idealización del Itamaraty, dirigido por el Barón de Rio Branco, como órgano supremo de irradiación o afirmación del prestigio de Brasil en el continente, en particular, e en el exterior, en general" (FREYRE, 2000, p. 140).

Sin embargo, interesa a nosotros en este breve artículo discutir no el legado del Barón, lo que se hace extensamente, pero sí su principal influencia, su padre, el

Candido o también Sobrados e Mucambos, de Freyre y Raizes do Brasil, de Buarque de Hollanda ambos de 1936.

3 Originalmente llamado Secretaria y después Ministerio de los Negocios Extranjeros bajo la administración imperial, ganó el sobrenombre de Itamaraty por quedarse en el palacio de mismo nombre de 1899 a 1970 . En el período imperial se utiliza la nomenclatura de MNE para hablar de la institución, considerando que así la era nombrada.

4 Sobre el Barón hay mucho material. Se puede mencionar Martinov, Мартинов Б. Ф., Загадка Барона Рио Бранко, Исторические Очерки. М.: ИЛА РАН, 2013. Martinov, B. F., Zagadka Barona Rio Branco, Istoritcheskie Ocherki. Moskva, ILA RAN, 2013. (Rio Branco's Puzzle, Historical Essays) o también Ricupero, RICUPERO, Rubens. Rio Branco: o Brasil no mundo. Rio de Janeiro: Contraponto/Petrobras, 2000. 
Vizconde de Rio Branco (FRANCO, 2005, p. 19). Algunos opúsculos en su muerte, dos estudios biográficos, uno escrito por su hijo, el Barón, una tesis de Maestría y una tesis (FRANCO, 2005, p. 19-20) en el Instituto Rio Branco, ${ }^{5}$ estos son los únicos estudios sobre el Vizconde, el hombre que el Emperador Don Pedro II definió cuando dijo que no hubiera conocido "persona más inteligente y perspicaz" (MELLO, 2005, p. 11). En la manutención del Barón como lugar de memoria de la práctica diplomática y jurídica, adherimos a la tese de Patriota de Moura, segundo la cual los biógrafos del Patrono de la diplomacia brasileña han comunemente incorporado las biografías de los dos Paranhos en una intención de construir una mítica del diplomático-estadista, y así, en esta perspectiva el conocimiento sobre el Vizconde de Rio Branco tendría la función de componer, por medio de las ideas reunidas, del ejemplo y de las preocupaciones, la biografía de su hijo que se tornaría símbolo de la diplomacia brasileña (FRANCO, 2005, p. 19).

No obstante, en innúmeras ocasiones escribió el mítico Barón: “procedo, en este caso, cómo habría procedido mi padre” (PEREIRA, 2012, p. 9). ¿Cómo procedía el Vizconde? Buscaremos entonces analizar a los discursos del Vizconde en el Parlamento Imperial tras el tema de la diplomacia, en específico la cuestión platina, para que sea posible comprender su visión sobre el hacer diplomático y el papel de Brasil.

Joaquim Nabuco ${ }^{6}$ escribió de él como "el más moderado constante y inteligente defensor de los intereses de la nuestra posición" hablando de la diplomacia brasileña. Para Nabuco, Paranhos era "la más lúcida conciencia monárquica que tuvo el Reinado" (NABUCO, 1949, p. 187-188). Y también Machado de Assis, el más importante escritor brasileño, cuando, después de escuchar un discurso de más de ocho horas dijo de las palabras de Paranhos que "fue una de las más hondas impresiones que me dejo la elocuencia parlamentaria” (ALMEIDA, 2016, p. 248).

De una familia de comerciantes portugueses decadentes, nació José Maria da Silva Paranhos en Salvador en el 16 de marzo de 1819. Estudió en la Escuela de la Marina y después se hizo doctor en ciencias matemáticas en 1846 por la Escuela Militar, donde fue también profesor catedrático. Periodista, político y diplomático, inició su carrera por el Partido Liberal, después cambiando al Partido Conservador. Presidente del Consejo de Ministros de 1871 a 1875, fue también Ministro de la Hacienda, Ministro de la Guerra, de la Marina y de los Negocios Extranjeros, creando y también ejerciendo el cargo de consultor jurídico del MNE (PIMENTEL, 2013, p. 261-262). Su trayectoria de privaciones económicas y ausencia de formación jurídica lo diferencia (FRANCO, 2005, p. 15-16) inmensamente de sus predecesores, contemporáneos o sucesores, con raras

En homenaje al Barón, se bautizó la academia diplomática de Brasil (1945), la segunda más antigua del mundo.

6 Joaquim Nabuco (1849-1910) fue un proeminente jurista, historiador, político, diplomático y periodista. 
excepciones, pues construye el derecho internacional de Brasil y busca trasladar su visión de un interés nacional a la política imperial sin tener las orígenes necesarias para integrar y operar la estructura patrimonialista del estado imperial, especialmente en relación a la diplomacia del Plata, eminentemente política, diferenciando-se de la diplomacia con Europa, como explana Cheibub:

En la relación con Europa, por no envolver cuestiones de sobrevivencia, prevalecía una diplomacia de rutina, más profesional, llevada a cabo por individuos que empezaban a constituir un grupo de diplomáticos profesionales. En el trato de las cuestiones con los vecinos, entretanto, por envolver cuestiones de soberanía, predominaba la acción política militar, conducida por eminentes miembros de la élite política imperial (CHEIBUB, 1985, p. 116-117).

2. La importancia del interés nacional para Paranhos

Desde los fines de los años 1840, con la conciliación política interna y la estabilización en la Corte, los Negocios del Plata se convierten en la prioridad de la diplomacia imperial (SCHWARCZ, 1998, 297), ahora apta a planear y actuar con mayor libertad. Garantizar la paz en la región, el equilibrio de fuerzas entre las repúblicas, contra la influencia de Buenos Ayres, la definición de las fronteras imperiales por el uti possidetis y la libre navegación en la bacía del Plata, que integraba la Corte de Sán Cristóbal con la Provincia de Mato Grosso y con el pulsante comercio de la región eran las prioridades imperiales. Las sucesivas misiones diplomáticas y debates en estos temas fueron una escuela política para la élite imperial (LYRA, 1977, p. 207), incluyendo Paranhos.

En el primero de Junio de 1860 debate Paranhos con el Diputado Martinho Campos, que critica a los intereses y beneficios de la política imperial en el Plata:

aunque cuando era cierto que en los Estados del Plata no tenemos que ver sino intereses comerciales, a la misma manera, nuestras relaciones con ellos no podrían dejar de ser, también, políticas; pues son las relaciones políticas, cuando bien cultivadas, que aseguran la paz y la amistad de los pueblos y de sus gobiernos. Y, sin paz, sin amistad, sin benevolencia recíproca, sufren los intereses comerciales, como los intereses de cualquier otro orden (RIO BRANCO, 2005, p. 144).

Como buscamos comprender el personaje histórico como un modelo o tipo ideal, que condiciona las relaciones exteriores de Brasil en diálogo con las internas, debemos destacar la coherencia profunda, de larga duración. Mirar al tipo ideal weberiano, que crea relaciones inteligibles proprias bajo los grandes acontecimientos, con significado 
en nuestro presente (LAFER, 2001, p. 14). En 5 de junio de 1865, Paranhos hace en tal aspecto un ejercicio reflexivo en el Parlamento:

Siempre profesé, y todavía hoy profeso, que la política externa no debe estar sujeta a las vicisitudes de la política interna, que debe tener principios tradicionales y fijos, comunes a todos los partidos; $\mathrm{y}$, seguramente, señores, desgraciado el país que, después de tantos años de independencia, como posee Brasil, ni a lo menos tenga, todavía, principios fijos sobre su política externa en relación a los Estados limítrofes. Esta opinión mía parecía y me parece incontestable en circunstancias como aquellas en que entonces estábamos, con la inminencia de una guerra externa. Ante el enemigo externo, comprende y comprendo siempre que somos todos amigos y aliados (RIO BRANCO, 2005).

Se pone clara su visión, negación de un patrimonialismo existente en Brasil y Latinoamérica, que contamina la política externa uruguaya, paraguaya y de la Confederación. No son las ambiciones de los caudillos o de los caciques que deben guiar la diplomacia, pero un interés mayor y central. Sin embargo, tal interés debe considerar la manutención de la paz con las otras naciones, lo que explicita en el once de julio de 1862 , al decir que "Y, además, los intereses de un país civilizado, como Brasil, implícitamente comprenden los de las otras naciones" (RIO BRANCO, 2005, p. 208).

$\mathrm{Su}$ formación como matemático y también su actuación en la masonería pueden ayudar a delinear su creencia en el progreso del género humano, que definió en 1870 frente al Senado:

el cristianismo y la civilización moderna, que en él se funda, van estableciendo una fraternidad de sentimientos y intereses entre los pueblos, que tiende a acabar con el antagonismo de razas, con el ego[ismo de políticas retrógradas o ambiciones ilegítimas, [y] que, bajo el punto de vista de la religión y de la filosofía, todos los pueblos caminan para el mismo destino e se puede decir que constituyen una sola familia, esto es, la grande familia que se llama humanidad (RIO BRANCO, 2005, p. 468).

Se destaca aquí la similitud con una visión de paz perpetua como la kantiana. En este proceso de construcción de paz, el hacer político colectivo es para Paranhos fundamental, en un proceso de reconocimiento de las otras naciones como iguales y con los mismos derechos, que puede encontrar su origen tanto en el derecho internacional como en la filosofía.

A la vez, la filosofía nos remite a la visión kantiana del reconocimiento, el anerkennung del Otro como Ser, lo que se traslada en el derecho en el reconocimiento 
de otros Estados como soberanos y sujetos de derecho (BARRIO, 2018, p. 21). Es así también clara la influencia del pensamiento de Grotius en Paranhos, lo que veremos más evidente cuando el habla de las fronteras (LAFER, 2001, p. 76).

Continuando el ejercicio reflexivo bajo la visión de Paranhos, la diferenciación del sí mismo y el otro se traduce internacionalmente en una dialéctica de implicación mutua entre el externo y el interno -solo la estabilidad en la región permitirá al Imperio consolidar sus fronteras y buscar a sus objetivos internos como nación y a la afirmación de una identidad nacional, que es indisociable del progreso de la humanidad (CORRÊA, 2000, p. 29). Resume Lafer cuando dije que "con efecto, para Brasil la América del Sur no es una opción, sino, para hablar con Ortega y Gasset, la 'circunstancia' del nuestro yo diplomático" (LAFER, 2001, p. 52).

Para comprender el sí mismo brasileño, Paranhos debate la cuestión de las fronteras en el Plata, que analizaremos abajo. Será tras la justicia en la aplicación del derecho internacional que el buscará consolidar la identidad nacional brasileña -una búsqueda por el derecho perfecto.

\section{La preocupación con las fronteras}

De un debate en el cuatro de agosto de 1857, tenemos las palabras de Paranhos hablando de las negociaciones de límites con Paraguay, discutiendo los tratados de Madrid y Santo Ildefonso:

No tengo dudas que se fuera posible establecer una frontera preferible a esta (1777), pero nunca voy a aconsejar al gobierno imperial que, sin una necesidad absoluta de seguridad y policía para el Imperio y sus vecinos trate de obtener aumento de territorio, trate de llevar sus límites más aún de su derecho perfecto.

Nosotros no carecemos de territorio; carecemos, sí, de gente útil que puebla el vasto y bello territorio que poseemos. Es un preconcepto entre nuestros vecinos que el gobierno imperial busca ampliar sus dominios. El principio del uti possidetis, consagrado en el derecho de las gentes, que es la base del derecho territorial de casi todas las naciones, es considerado por algunos de nuestros vecinos como una creación sutil del gobierno imperial para aumentar su territorio. Consecuentemente, no pretendamos extender las nuestras fronteras más aún de lo que poseemos por derecho originario y por motivo de nuestras poses (RIO BRANCO, 205, p. 127). (énfasis añadido).

¿Qué es el derecho perfecto para Paranhos? ¿Cómo garantizar-lo? Son dos los puntos relevantes en su argumentación en este extracto para que sea posible responder 
a estas preguntas: el primero, la relevancia de la perspectiva de observación de los tratados de Madrid (1750) y Santo Ildefonso (1777), el segundo, la afirmación del principio del uti possidetis, implementado por Alexandre de Gusmão en el Tratado de Madrid (GOES FILHO, 2013, p. 68-69) y utilizado en los tratados siguientes.

Sobre esta posición, la perspectiva histórica dominante en la historiografía hispánica tiene buen ejemplo en Barrenechea, al comentar el uso de los tratados por la diplomacia imperial:

El tratado de San Ildefonso fue el último convenio celebrado entre España y Portugal, sobre delimitación de sus respectivas colonias. Era el tratado vigente al proclamarse la independencia de Sur América. El Brasil, sin embargo, siguiendo la tradición expansionista de los colonizadores portugueses, sobrepasó en muchos lugares la linea del Tratado de San Ildefonso. En las discusiones diplomáticas en las que países vecinos del Brasil intentaron hacer valer los derechos que les concedía el Tratado de San Ildefonso, el Brasil negó la validez y subsistência de este Tratado (PORRAS BARRENECHEA, 1981, p. 23).

Es necesario notar en Barrenechea el carácter político que influenciaba las relaciones de las repúblicas con el Imperio. Esto se resume en las palabras de Rosas, "Nuestro verdadero enemigo es el Imperio de Brasil, porque es un Imperio" (LYNCH, 1984, p. 366). Una falsa oposición entre el orden imperial, que sería por definición imperialista, y el caudillismo republicano.

De todo, la visión de construcción de un orden estable en el Plata bajo el derecho para Paranhos, ya mencionada en el excepto del 1857, puede ser resumida en las palabras del Embajador Sampaio Goes, dejando claro que no había un imperialismo expansionista por parte de Brasil, sino la ambición de, utilizando el uti possidetis, consolidar las fronteras existentes y garantizar la ocupación de la nación:

La doctrina brasileña, desarrollada en el Imperio, se basaba no al texto del Tratado de Santo Ildefonso, que era "preliminar" (como dice su título oficial) y después fue anulado por la guerra de 1801 (argumentamos siempre), pero si a su principio fundamental, que era el mismo del Tratado de Madrid, el uti possidetis. Santo Ildefonso iba a servir, si, pero solo como orientación suplementaria y, en aquellas áreas sin ocupación de ninguna de las partes implicadas, seguía la doctrina, formulada en su versión más completa por el Vizconde de Rio Branco, en memorando presentado al gobierno argentino, en 1857. En serio, y hasta que lográramos obtener, más tarde, al término de los grandes trabajos del segundo Rio Branco, fronteras perfectamente definidas en tratados bilaterales - era la pose que seguía a definir el territorio (GOES FILHO, 2013). 
Ahora que tenemos claro el locus standi de la diplomacia imperial, persiste la pregunta que mencionamos anteriormente- ¿Cómo garantizar la defensa de esta visión de mundo? Paranhos propone una construcción de una paz realista con soft o clever power (LAFER, 2001, p. 76), utilizando el derecho y la mediación, el diálogo diplomático como herramienta, pero está consciente de la necesidad de un lastre en el hard power. En el 6 de agosto de 1855, el dijo:

Mencionaré (...) que, en el nuestro país, la sabiduría y la prudencia del monarca que preside a los nuestros destinos ha, algunas veces, hecho preferir a los medios blandos y pacíficos para prevenir y extinguir las conmociones políticas. No es exacto que entre nosotros se considere la fuerza como el único medio de mantener el orden.

Soy partidario de los gobiernos fuertes y enérgicos; pero comprendo que la fuerza no consiste solo en el empleo de los medios materiales; comprendiendo que, muchas veces, se da prueba de coraje y de fuerza la autoridad que sepa emplear los medios blandos de preferencia al recurso extremo de la fuerza (RIO BRANCO, 2005, p. 74).

Sigue en el primero de junio de 1860, resaltando la observancia de la manutención frente a la expansión y también la necesidad de considerar los intereses de las otras naciones, en un ejercicio de alteridad:

No es el Brasil lo que más debe temer una guerra con los Estados del Plata; pero, por el mismo motivo tenemos consciencia de la nuestra fuerza, podemos ser moderados, benevolentes y mismo generosos, tanto cuanto estos sentimientos sean compatibles con la dignidad nacional e con los derechos y grandes intereses del Imperio. (...) Pido, entretanto, al noble diputado que ponga sus ojos sobre la carta geográfica del Imperio y de los Estados vecinos; que comprenda a las relaciones intimas en que se hallan estos pueblos y sus gobiernos; y, entonces, el nombre diputado verá que, más aún de los intereses comerciales, tenemos ahi intereses muy importantes de otro orden, intereses de seguridad, de paz, de protección a los súbditos brasileños $y$ de sus propriedades. (RIO BRANCO, 2005, p. 143-144) (énfasis añadido).

Aquí se hace presente la neutralidad limitada (CERVO, 1983, p. 112-113). El comprehende el intervencionismo no como derecho absoluto, pero sí como derecho condicionado a la defensa de sus intereses esenciales o de su honor (RIO BRANCO, 2005, p. 253). Aunque sea posible argumentar que es posible justificar las mayores barbaridades bajo la necesidad de defensa del honor o de intereses vitales al Estado, Paranhos diferencia 
su pensamiento cuando defiende frenos y responsabilidades que limiten el ejercicio del derecho de utilizar la violencia, en el 5 de junio de 1865:

\begin{abstract}
El las circunstancias actuales del mundo, no basta a un gobierno que invoque a los derechos de beligerante. Por cierto, compete a cada gobierno sustentar a su dignidad y sus legítimos intereses cuando lo juzgue necesario, por medio de la fuerza; pero, hoy, relacionadas como están todas las naciones, en el momento en que se llega la civilización y la fraternidad humanas, es obligación del gobierno que recurre a la fuerza, que se lanza en una guerra, tener los medios precisos para la termine el más brevemente posible; cuando no, los intereses de los neutros claman y la opinión pública le va a forzar a recibir alguna transacción que traiga la paz (RIO BRANCO, 2005, p. 333).
\end{abstract}

\title{
4. La pax brasiliana de Rio Branco
}

Hemos explorado brevemente las posiciones del Vizconde sobre la afirmación de la identidad brasileña. En la dialéctica del recuerdo y del olvido de que habla Nora, percibimos la permanencia de su legado: Es un intérprete auténtico de su tiempo, aunque representante sui generis de la elite imperial, siendo su obra política, jurídica y literaria fundamental para comprender el apogeo del Imperio, la Guerra de Paraguay, la esclavitud y la política imperial; Se mantiene actual, aunque su legado se mezcle y sea eclipsado por el de su hijo en el culto institucionalizado a la memoria del Barón en el Itamaraty; Las categorías de comprensión históricas que elabora -el interés nacional, la isonomía entre los Estados, el uso responsable de la fuerza- se hacen aplicables a realidades diversas de las que les originaron, en especial la manutención de fronteras de cooperación en lugar de fronteras de separación, uso responsable de la fuerza militar y de igualdad entre las naciones.

En el espíritu de la neutralidad limitada, el gobierno imperial que entra en una disputa de contornos de una gunboat diplomacy (BARRIO, 2018, p. 108) con Paraguay es el mismo que prefiere no bombardear a Montevideo (RIO BRANCO, 2005, p. 398) y con eso consigue ganar la simpatía de los uruguayos y argentinos contra Paraguay. Aunque a partir de el aumento de la tensión con Paraguay crezca la tendencia a un intervencionismo reacio, Paranhos se pone entre el Derecho y el Poder. El propio ejemplo de la defensa de Paranhos de los derechos de Paraguay (DIAS DUARTE; DOMSCHKE-TOMIC; LEAL; BARRETO; MINHONI; MOTTA MARTINS, 2018, p. 4) frente a Argentina después del fin de la guerra deja claro los valores que orientan el Vizconde, pero es el proprio que mejor resume su visión diplomática en el Plata, cuando en misión en Buenos Aires, en el 1857, "no busco alianzas guerreras -declara-, sino la paz para todos. Libertad de los ríos, 
estabilidad de las naciones, progreso y civilización de los países ribereños y vecinos". (CÁRCANO, 2018. p. 231).

En una mezcla de un realismo grociano con un idealismo kantiano, busca en la "sociedad internacional un ingrediente positivo de sociabilidad que permite hacer frente, por medio del Derecho y de las organizaciones internacionales, con el conflicto y la cooperación entre los Estados y así reducir al ímpetu de la "política del poder" (LAFER, 1999, p. 17) pero orienta sus objetivos bajo a una creencia en el consenso, el progreso de la humanidad y la armonía del concierto de las naciones bajo la Paz Perpetua (NABUCO, 1998, p. 511; ACCIOLY, SILVA; CASELLA, 2015, p. 874-879). Lo resume Pandiá Calógeras:

Grande y noble fuera la taera cumplida por el Imperio. Estaba el Brasil bajo la amenaza de la desintegración por factores múltiplos y, todavía, se logró mantener unido (...) En cuanto a las relaciones exteriores, la misma marcha ascensional era notada (...) La hostilidad generalizada contra el Imperio por parte de las Repúblicas sudamericanas (...) iba a los pocos cediendo, y vino a ser substituida por un ambiente de confianza mutua. De la Europa como de la América del norte, pruebas idénticas de crédito político e internacional llegaban al Brasil (...) Ninguna duda restaba sobre la posición eminente del Imperio en la América del Sur y nuevas demostraciones de tal sentimiento era prodigalizadas en el Congreso de Montevideo sobre el Derecho Internacional Privado y en la Primera Conferencia Panamericana de Washington, en el 1889. (PIMENTEL, 2013. p. 30).

En el tiempo longo (LE GOFF, 2006, p. 54) de las tensiones del Plata, que concentra las fuerzas profundas (DUROSELLE, 2000, p. 163) de la historia colonial y los proyectos nacionales, Paranhos trasciende el mero burócrata weberiano: Estadista, comprende las fuerzas y también su papel de no solo canaliza-las, pero de tomar el momento histórico para crear un nuevo escenario, nuevos paradigmas. El Embajador Ricupero explana que conceptos como la aversión a la injerencia y la valorización de la negociación y de las soluciones pacíficas "se incorporaron de tal manera al discurso diplomático brasileño, que toda la gente cree que no hubo en esa evolución novedad alguna, que siempre pasó así". (RICUPERO, 2002, p. 90). Se pierde la conciencia de las orígenes de la práctica en la perfomance diplomática (DA MATTA, 1983, p. 42-44).

"El mentor de la nuestra política diplomática" (LIMA, 1921, p. 229), el Vizconde de Rio Branco se convirtió en un lugar de memoria. Una diplomacia pragmática pero orientada por la Justicia es su mayor legado: 
Las victorias militares son por veces gloriosas, tienen también sus ventajas especiales; pero yo siempre voy a preferir los triunfos de la paz, cuando ellos puedan ser igualmente honrosos. (RIO BRANCO, 2005. p. 143).

São Paulo, novembro de 2019.

\section{Referências}

ACCIOLY, Hildebrando Pompeo Pinto; SILVA, Geraldo Eulálio do Nascimento e; CASELLA, Paulo Borba. Manual de direito internacional público. 21. ed. São Paulo: Saraiva, 2015.

ALMEIDA, Paulo Roberto. A construção do direito internacional do Brasil a partir dos pareceres dos consultores jurídicos do Itamaraty: do Império à República. Cadernos de Política Exterior, Brasília, DF, ano 2, n. 4, p. 241-298, jul./dez. 2016. Disponível em: http://funag.gov.br/biblioteca/ download/1186-cadernos-de-politica-exterior-ano-2-volume-4.pdf.

BARBOSA, Rui. Rio Branco. In: FUNAG. Centro de História e Documentação Diplomática (org.). O Barão do Rio Branco visto por seus contemporâneos: série de artigos publicados pela Revista Americana, em abril de 1913. Brasília: FUNAG, 2002.

BARRIO, Cesar de Oliveira Lima. O Império do Brasil e a política de intervenção no Rio da Prata (1843-1865). Brasília: FUNAG, 2018.

CÁRCANO, Ramón José. Guerra del Paraguay: orígenes y causas. Buenos Aires: Buena Vista Editora, 2018.

CERVO, Amado Luiz. Relações internacionais do Brasil. In: . (org.). O desafio internacional: a política exterior do Brasil de 1930 a nossos dias. Brasília: Universidade de Brasília, 1994.

CHEIBUB, Zairo. Diplomacia e construção institucional: o Itamaraty em uma perspectiva histórica. Dados: Revista de Ciências Sociais, Rio de Janeiro, v. 28, n. 1, p. 113-131, 1985.

CORRÊA, Luiz F. de Seixas. Diplomacia e história: política externa e identidade nacional brasileira. Politica Externa, São Paulo, v. 9, n. 1, p. 22-32, jun./ago. 2000.

DA MATTA, Roberto. Carnavais, malandros e heróis: para uma sociologia do dilema brasileiro. Rio de Janeiro: Zahar, 1983.

DIAS DUARTE, Caio Henrique; DOMSCHKE-TOMIC, Tomás E.; LEAL, Débora; BARRETO, Lucas; MINHONI, Felipe; MOTTA MARTINS, Ítalo. Geografia das paixões: política externa e defesa nacional. In: CONGRESSO ACADÊMICO SOBRE DEFESA NACIONAL, 15., 2018, Pirassununga, SP. Anais... Brasília: Ministério da Defesa, 2018. 
DORATIOTO, Francisco. O Visconde do Rio Branco: soberania, diplomacia e força. In: PIMENTEL, José Vicente de Sá (org.). Pensamento diplomático brasileiro: formuladores e agentes da política externa (1750-1964). Brasília: FUNAG, 2013. v. 1, p. 263-299.

DUROSELLE, Jean-Baptiste. Todo império perecerá: teoria das relações internacionais. Tradução de Ane Lize Spaltemberg de Seiqueira Magalhães. Brasília: Universidade de Brasília, 2000.

FONSECA JÚNIOR, Gelson. A legitimidade e outras questões internacionais: poder e ética entre as nações. São Paulo: Paz e Terra, 1998.

FREYRE, Gilberto. Ordem e progresso. In: SANTIAGO, Silviano. Intérpretes do Brasil. Rio de Janeiro: Nova Aguilar, 2000. v. 3.

GOES FILHO, Synesio Sampaio. Alexandre de Gusmão: o estadista que desenhou o mapa do Brasil. In: PIMENTEL, José Vicente de Sá (org.). Pensamento diplomático brasileiro: formuladores e agentes da política externa (1750-1964). Brasília: FUNAG, 2013. v. 1. p. 53-85.

LAFER, Celso. A identidade internacional do Brasil e a política externa brasileira: passado, presente e futuro. São Paulo: Perspectiva, 2001.

LAFER, Celso. Comércio, desarmamento, direitos humanos: reflexões sobre uma experiência diplomática. São Paulo: Paz e Terra, 1999.

LE GOFF, Jacques. L'histoire nouvelle. In: Le Goff, Jacques (dir.). La Nouvelle Histoire. Bruxelles: Complexes, 2006.

LIMA, Manuel de Oliveira. O movimento da Independência, 1821-1822. São Paulo: Melhoramentos, 1921.

LYNCH, John. Juan Manuel de Rosas. Buenos Aires: Emecé Editores, 1984.

LYRA, Heitor. História de Dom Pedro II. São Paulo: EDUSP, 1977.

MELLO, Fernando Figueira de. O Visconde do Rio Branco: entre a biografia estabelecida e a reconstrução da biografia. In: FRANCO, Alvaro da Costa (org.). Com a palavra, o Visconde do Rio Branco: a política exterior no parlamento imperial. Rio de Janeiro: CHDD; Brasília: FUNAG, 2005. p. 11-22.

NABUCO, Joaquim. Minha formação. Introdução de Gilberto Freyre. Brasília: Senado Federal, 1998.

NABUCO, Joaquim. Um estadista do Império. São Paulo: IPE, 1949.

NORA, Pierre. Entre mémoire et histoire. In: . Les lieux de mémoire. Paris: Gallimard, 1984. v. 1 .

PEREIRA: Manoel Gomes. (org.). Barão do Rio Branco: 100 anos de memória. Brasília: FUNAG, 2012. 
PIMENTEL, José Visconde de Sá (org.). Pensamento diplomático brasileiro: formuladores e agentes da política externa (1750-1964). Brasília: FUNAG, 2013. v. 1.

PORRAS BARRENECHEA, Raúl; WAGNER REYNA, Alberto. Historia de los límites del Peru. Lima: Editorial Universitaria, 1981.

RICUPERO, Rubens. Rio Branco, definidor de valores nacionais. In: CARDIM, Carlos Henrique; ALMINO, João. (org.). Rio Branco, a América do Sul e a modernização do Brasil. Rio de Janeiro: EMC, 2002. p. 79-98.

RIO BRANCO, José Maria da Silva Paranhos, Visconde do, 1819-1880. Com a palavra, o Visconde do Rio Branco: a política exterior no Parlamento Imperial. Alvaro da Costa Franco (org.). Rio de Janeiro: CHDD; Brasília: FUNAG, 2005.

RODRIGUES, José Honório. Interêsse nacional e politica externa. Rio de Janeiro: Civilização Brasileira, 1966. p. 54.

SÁ, Dominichi Miranda de. A ciência como profissão: médicos, bacharéis e cientistas no Brasil (1895-1935). Rio de Janeiro: Fiocruz, 2006.

SCHWARCZ, Lilia Moritz. As barbas do imperador: D. Pedro II, um monarca nos trópicos. São Paulo: Companhia das Letras, 1998.

SCHWARZ, Roberto (org.). Ao vencedor as batatas. São Paulo: Duas Cidades, 1992.

SOUZA, Antonio Candido de Mello e. Os parceiros do Rio Bonito: estudo sobre o caipira paulista e a transformação dos seus meios de vida. São Paulo: EDUSP, 2017. 
